PACS: 72.20.Dp; 72.20.Fr; 72.20.My

\title{
Investigation of the physical properties of multicomponent solid solutions $\mathrm{Hg}_{1-\mathrm{x}-\mathrm{y}-\mathrm{z}} \mathrm{A}_{\mathrm{x}} \mathrm{B}_{\mathrm{y}} \mathrm{C}_{\mathrm{z}} \mathrm{Te}$
}

\author{
S.E. Ostapov, I.N. Gorbatyuk, V.V. Zhikharevich \\ Yu. Fed'kovich Chernivtsi National University, 2, Kotsyubinsky str., 58012 Chernivtsi, Ukraine
}

\begin{abstract}
This paper presents theoretical research on the basic band parameters and galvanomagnetic phenomena in multicomponent solid solutions $\operatorname{Hg}_{1-\mathrm{x}-\mathrm{y}} \mathrm{Cd}_{\mathrm{x}} \mathrm{Mn}_{\mathrm{y}} \mathrm{Te}$, $\mathrm{Hg}_{1-\mathrm{x}-\mathrm{z}} \mathrm{Cd}_{\mathrm{x}} \mathrm{Zn}_{\mathrm{z}} \mathrm{Te}$ and $\mathrm{Hg}_{1-\mathrm{x}-\mathrm{y}-\mathrm{z}} \mathrm{Cd}_{\mathrm{x}} \mathrm{Mn}_{\mathrm{y}} \mathrm{Zn}_{\mathrm{z}} \mathrm{Te}$, resulting in the empirical formulae for the energy gap and the intrinsic carrier concentration of these materials in a wide range of temperatures and compositions. The effective mechanisms of charge carrier scattering, concentration and activation energy of acceptor impurities have been determined. The results of theoretical research are in a good agreement with the experimental and literature data.
\end{abstract}

Keywords: solid solutions, electronic transport, galvanomagnetic effects, band structure.

Manuscript received 03.12.04; accepted for publication 18.05.05.

\section{Introduction}

Solid solutions $\mathrm{Hg}_{1-\mathrm{x}} \mathrm{Cd}_{\mathrm{x}} \mathrm{Te}$ offer a number of unique physical and electrooptical properties making such materials attractive for development of IR detectors. However, their wide use is prevented by the instability of this material. It was theoretically shown by Sher [1] that this instability is caused by rather large differences between the atomic radii of $\mathrm{Cd}$ and $\mathrm{Hg}$. Hence, material stability should increase with introduction of $\mathrm{Mn}$ or $\mathrm{Zn}$, since their atomic radii are closer to that of $\mathrm{Hg}$.

Despite the promising character of such materials as $\mathrm{Hg}_{1-\mathrm{x}-\mathrm{y}} \mathrm{Cd}_{\mathrm{x}} \mathrm{Mn}_{\mathrm{y}} \mathrm{Te}$ and $\mathrm{Hg}_{1-\mathrm{x}-\mathrm{z}} \mathrm{Cd}_{\mathrm{x}} \mathrm{Zn}_{\mathrm{z}} \mathrm{Te}$, their basic parameters due to the difficulty of obtaining pure and high-quality crystals are not adequately studied. First of all, it is true for the energy gap, intrinsic carrier concentration and effective mass of electrons. Even to a greater extent, it refers to $\mathrm{Hg}_{1-\mathrm{x}-\mathrm{y}-\mathrm{z}} \mathrm{Cd}_{\mathrm{x}} \mathrm{Mn}_{\mathrm{y}} \mathrm{Zn}_{\mathrm{z}} \mathrm{Te}$, as long as this is absolutely new material for which the above parameters are unknown at all. All this is related in full measure to charge carrier scattering mechanisms, as well as to impurity states in crystals.

\section{Theoretical calculations}

The basic band parameters of multicomponent solid solutions can be calculated using the method proposed by S. Williams [2], where the initial solution is regarded as a combination of three ternary solutions. But as long as this procedure is rather awkward and does not yield even empirical relationships, we have used a simpler calculation method [3]. The essence of this method is that multicomponent material is represented as a combination of two simpler materials. Using this procedure, the formula for energy band, for example, of $\mathrm{Hg}_{1-\mathrm{x}-\mathrm{y}} \mathrm{Cd}_{\mathrm{x}} \mathrm{Mn}_{\mathrm{y}} \mathrm{Te}$, will be as follows:

$E_{g}\left(\mathrm{Hg}_{1-\mathrm{x}-\mathrm{y}} \mathrm{Cd}_{\mathrm{x}} \mathrm{Mn}_{\mathrm{y}} \mathrm{Te}\right)=0.5 E_{g}\left(\mathrm{Hg}_{1-2 \mathrm{x}} \mathrm{Cd}_{2 \mathrm{x}} \mathrm{Te}\right)+$

$+0.5 E_{g}\left(\mathrm{Hg}_{1-2 \mathrm{y}} \mathrm{Mn}_{2 \mathrm{y}} \mathrm{Te}\right)$,

and the energy gap of $\mathrm{Hg}_{1-\mathrm{x}-\mathrm{z}} \mathrm{Cd}_{\mathrm{x}} \mathrm{Zn}_{\mathrm{z}}$ Te can be calculated:

$E_{g}\left(\mathrm{Hg}_{1-\mathrm{x}-\mathrm{y}-\mathrm{z}} \mathrm{Cd}_{\mathrm{x}} \mathrm{Mn}_{\mathrm{y}} \mathrm{Zn}_{\mathrm{z}} \mathrm{Te}\right)=$

$=0.5 E_{g}\left(\mathrm{Hg}_{1-\mathrm{x}-2 \mathrm{y}} \mathrm{Cd}_{\mathrm{x}} \mathrm{Mn}_{2 \mathrm{y}} \mathrm{Te}\right)+$

$+0.5 E_{g}\left(\mathrm{Hg}_{1-\mathrm{x}-2 \mathrm{z}} \mathrm{Cd}_{\mathrm{x}} \mathrm{Zn}_{2 \mathrm{z}} \mathrm{Te}\right)$.

Using the empirical formulae of the energy gap for HgCdTe [4], HgZnTe [5], and HgMnTe [6], we get for HgCdMnTe:

$E_{g}(x, y, T)=-0.302+5.125 \cdot 10^{-4} T-$
$-(x+2.287 y) \cdot 10^{-3} T+1.93(x+2.197 y)-$
$-1.62\left(x^{2}+2.728 y^{2}\right)+0.272\left(12.235 x^{3}-y^{3}\right)$,

and for $\mathrm{HgCdZnTe:}$

$E_{g}(x, y, T)=-0.301+1.93 x+2.291 \cdot 10^{-2} y^{1 / 2}+$

$+2.731 y-1.62 x^{2}+5.35 \cdot 10^{-4} T\left(1-2 x-0.35 y^{1 / 2}-\right.$

$-1.28 y)+3.328 x^{3}-1.248 y^{2}+2.132 y^{3}$,

and for $\mathrm{Hg}_{1-\mathrm{x}-\mathrm{y}-\mathrm{z}} \mathrm{Cd}_{\mathrm{x}} \mathrm{Mn}_{\mathrm{y}} \mathrm{Zn}_{\mathrm{z}} \mathrm{Te}$ :

$E_{\mathrm{g}}(x, y, z, T)=-0.289+1.93(x+1.96 y+1.415 z)+$

$+4 \cdot 10^{-4} T\left(1-2.675 x-0.504 z^{0.5}-1.709 z-7.013 y\right)-$

$-1.62\left(x^{2}+1.553 z^{2}\right)+3.328\left(x^{3}+2.563 z^{3}\right)$.

Calculated by the formulae $(3-5)$, the energy gaps of multicomponent semiconductor solid solutions showed a good agreement with the experimental data (see Table 1). The energy gap of $\mathrm{Hg}_{1-\mathrm{x}-\mathrm{y}-\mathrm{z}} \mathrm{Cd}_{\mathrm{x}} \mathrm{Mn}_{\mathrm{y}} \mathrm{Zn}_{\mathrm{z}} \mathrm{Te}$ samples was determined from the optical transmission curves.

As can be seen from the table, the empirical 
formulae (2)-(4) describe well the experimental data for all investigated materials at various temperatures.

Based on the results obtained, the intrinsic carrier concentration, the Fermi level position and the effective mass of electrons for materials under study were calculated. The calculations followed the procedure described in [6].

Counting the energy from the bottom of conduction band, for electron concentration in conduction band in conformity with the Kane model [9] it can be written:

$n=\frac{2 N_{c}}{\sqrt{\pi}} \int_{0}^{\infty} \frac{z^{1 / 2}(1+z / \Phi)^{1 / 2}(1+2 z / \Phi) d z}{1+\exp (z-\eta)}$,

where $N_{c}$ is effective density of states in conduction band, $\Phi=E_{g} / k_{\mathrm{B}} T$ is the reduced energy gap, $\eta=F / k_{\mathrm{B}} T$ is the reduced Fermi energy. In this case, the effective mass of electrons near the bottom of the conduction band is described by the expression:

$m^{*}{ }_{e}=m_{0}\left[1+E_{P} \frac{E_{g}+2 \Delta / 3}{E_{g}\left(E_{g}+\Delta\right)}\right]^{-1}$.
Here, $E_{P}=2 m_{0} P^{2} / \hbar^{2}, \Delta$ is the value of the spin-orbit splitting of bands.

The hole concentration in the valence band was calculated in the regular way:

$p=4 \pi\left(\frac{2 k_{\mathrm{B}} T m_{h h}^{*}}{h^{2}}\right)^{3 / 2} F_{1 / 2}(\eta+\Phi)$,

where $m_{h h}^{*}$ is the effective mass of heavy holes, $F_{1 / 2}(\eta+\Phi)$ is the Fermi - Dirac integral. The values of the spin-orbit splitting $\Delta$, as well as the effective mass of heavy holes in the calculations were assumed to be equal: $\Delta=1 \mathrm{eV}, m_{h h}^{*}=0.55 m_{0}$.

The intrinsic carrier concentration was calculated from the solution of the electroneutrality equation for intrinsic semiconductor. Our comparison of the resulting values $n_{i}$ with the experimental ones allows us to propose the empirical formula for the intrinsic carrier concentration inherent to all the materials considered:

$n_{\mathrm{i}}(x, y, z, T)=(A+B x+C y+D z+E T(1+x+y+z)) \times$

$\times 10^{14} E_{g}{ }^{0.75} \cdot T^{1.5} \exp \left(-E_{g} / 2 k T\right)$,

Table 1. Comparison of calculated and experimental $E_{g}$ for materials studied.

\begin{tabular}{|c|c|c|c|c|c|c|c|}
\hline Material & $\mathrm{x}$ & $\mathrm{y}$ & $\mathrm{z}$ & $\begin{array}{l}T, \\
\mathrm{~K}\end{array}$ & $\begin{array}{c}E_{g} \text { theor., } \\
\mathrm{eV}\end{array}$ & $\begin{array}{c}E_{g} \text { exper., } \\
\text { eV }\end{array}$ & Source \\
\hline \multirow{4}{*}{ HgCdMnTe } & 0.215 & 0.022 & - & \multirow{4}{*}{7} & 0.17 & 0.18 & \multirow{4}{*}{ [7] } \\
\hline & 0.107 & 0.016 & - & & -0.065 & -0.07 & \\
\hline & 0.069 & 0.012 & - & & -0.125 & -0.13 & \\
\hline & 0.012 & 0.007 & - & & -0.25 & -0.26 & \\
\hline \multirow{4}{*}{$\mathrm{HgCdZnTe}$} & 0.07 & - & 0.17 & \multirow{4}{*}{95} & 0.301 & 0.328 & \multirow{4}{*}{ [8] } \\
\hline & 0.07 & - & 0.2 & & 0.383 & 0.374 & \\
\hline & 0.07 & - & 0.16 & & 0.276 & 0.277 & \\
\hline & 0.12 & - & 0.18 & & 0.406 & 0.409 & \\
\hline \multirow{3}{*}{ HgCdMnZnTe } & 0.213 & 0.031 & 0.02 & \multirow{3}{*}{300} & 0.300 & 0.304 & \\
\hline & 0.2 & 0.027 & 0.017 & & 0.267 & 0.27 & \\
\hline & 0.135 & 0.02 & 0.01 & & 0.14 & 0.145 & \\
\hline
\end{tabular}

Table 2. Coefficients of formula (6) for various materials.

\begin{tabular}{|c|c|c|c|c|c|}
\hline Material & $\mathrm{A}$ & $\mathrm{B}$ & $\mathrm{C}$ & $\mathrm{D}$ & $\mathrm{E}$ \\
\hline $\mathrm{Hg}_{1-\mathrm{x}-\mathrm{y}} \mathrm{Cd}_{\mathrm{x}} \mathrm{Mn}_{\mathrm{y}} \mathrm{Te}$ & 5.84 & -4.42 & 2.87 & 0 & $2.53 \cdot 10^{-3}$ \\
\hline $\mathrm{Hg}_{1-\mathrm{x}-\mathrm{z}} \mathrm{Cd}_{\mathrm{x}} \mathrm{Zn}_{\mathrm{z}} \mathrm{Te}$ & 6.48 & -4.42 & 0 & -6.54 & $1.42 \cdot 10^{-3}$ \\
\hline $\mathrm{Hg}_{1-\mathrm{x}-\mathrm{y}-\mathrm{z}} \mathrm{Cd}_{\mathrm{x}} \mathrm{Mn}_{\mathrm{y}} \mathrm{Zn}_{\mathrm{z}} \mathrm{Te}$ & 6.95 & -4.42 & 2.87 & -6.54 & $1.96 \cdot 10^{-3}$ \\
\hline
\end{tabular}




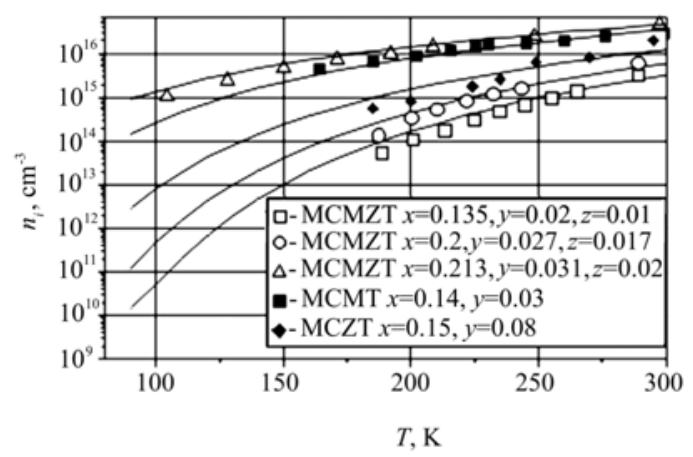

Fig. 1. Temperature dependences of the intrinsic carrier concentration as compared to the experiment. Solid curves calculations by the formula (6).

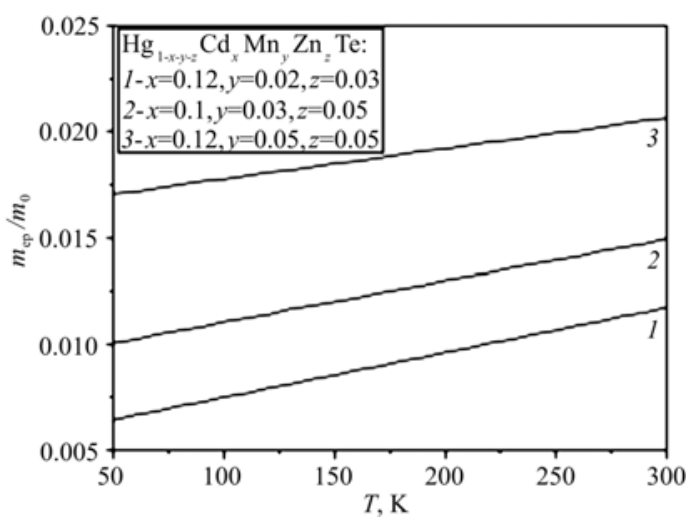

Fig. 2. Effective mass of electrons in $\mathrm{Hg}_{1-\mathrm{x}-\mathrm{y}-\mathrm{z}} \mathrm{Cd}_{\mathrm{x}} \mathrm{Mn}_{\mathrm{y}} \mathrm{Zn}_{\mathrm{z}} \mathrm{Te}$, calculated by the formula (4).

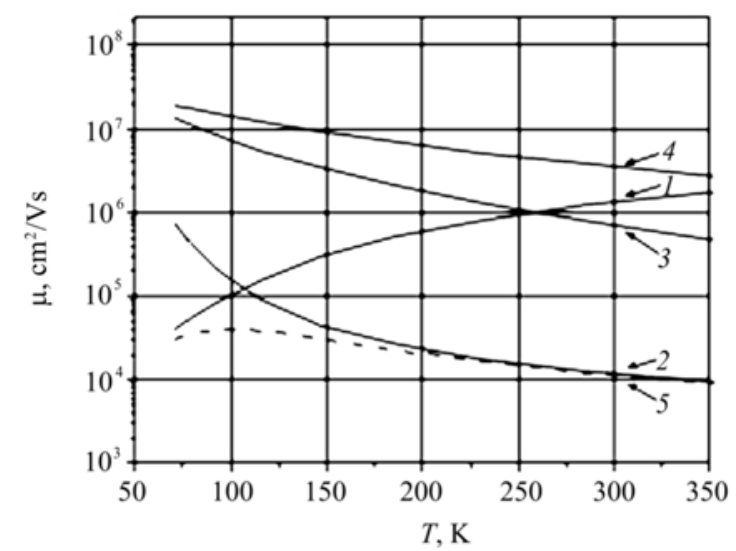

Fig. 3. Electron effective mass of totally degenerated HgCdMnTe vs composition.

The comparison of the intrinsic carrier concentration calculated by the formula (6) with the experimental data (see Fig. 1) shows that in all three cases, there is a good agreement with the experiment in the temperature range 50 to $350 \mathrm{~K}$ within a wide composition range.

The effective mass of electrons calculated by the formula (4) follows a linear law in the entire temperature range (Fig. 2).
The effective mass of electrons in the case of full degeneracy was calculated as follows [9]:

$$
\begin{aligned}
& \left(\frac{m_{e}^{*}}{1-m_{e}^{*}}\right)^{2}=32.5 \cdot 10^{-32} E_{g}^{2} / P^{4}+ \\
& +8.27 \cdot 10^{-30} n_{i}^{2 / 3} / P^{2},
\end{aligned}
$$

where $P$ is the matrix element of the angular momentum operator. The value $P$ for $\mathrm{Hg}_{1-\mathrm{x}-\mathrm{y}-\mathrm{z}} \mathrm{Cd}_{\mathrm{x}} \mathrm{Mn}_{\mathrm{y}} \mathrm{Zn}_{\mathrm{z}}$ Te was calculated by the same algorithm as the energy gap. Fig. 3 shows the results of calculation of the effective mass of electrons in the completely degenerated case for $\mathrm{Hg}_{1-\mathrm{x}-\mathrm{y}-\mathrm{z}} \mathrm{Cd}_{\mathrm{x}} \mathrm{Mn}_{\mathrm{y}} \mathrm{Zn}_{\mathrm{z}} \mathrm{Te}$. It can be seen that, in the range of compositions that are of practical interest (the righthand side of the plot), the effective mass is also almost linear.

Similar results in the calculation of effective masses are also obtained for other semiconductor solid solutions studied.

\section{Research on kinetic coefficients}

As regard to the above research on the band parameters, we have also calculated mobility, conductivity and Hall coefficient in semiconductor solid solutions $\mathrm{Hg}_{1-\mathrm{x}-\mathrm{y}-\mathrm{z}} \mathrm{A}_{\mathrm{x}} \mathrm{B}_{\mathrm{y}} \mathrm{C}_{\mathrm{z}} \mathrm{Te}$ and made a comparison with the experimental data.

The expressions for charge carrier relaxation times restricted due to scattering by ionized impurities, polar optical phonons, acoustic phonons and disorder potential, respectively, have the form [10]:

$$
\begin{aligned}
\tau_{\mathrm{im}} & =\frac{\hbar \chi^{2}}{2 \pi e^{4} N_{i} F_{\mathrm{im}}} \kappa^{2} \frac{\partial \varepsilon}{\partial \kappa}, \\
\tau_{\mathrm{op}} & =\frac{\hbar \chi^{*}}{2 e^{2} \kappa_{0} T F_{\mathrm{op}}} \frac{\partial \varepsilon}{\partial \kappa}, \\
\tau_{\mathrm{ac}} & =\frac{\hbar \pi \rho v_{/ /}^{2}}{E^{2} \kappa_{0} T F_{\mathrm{ac}}} \frac{1}{\kappa^{2}} \frac{\partial \varepsilon}{\partial \kappa}, \\
\tau_{\mathrm{dis}} & =\frac{\hbar \pi N_{0}}{W F_{\mathrm{dis}}} \frac{1}{\kappa^{2}} \frac{\partial \varepsilon}{\partial \kappa},
\end{aligned}
$$

where $\chi=\chi_{s}+\chi_{\infty}$ is the sum of static and high-frequency dielectric constants of material; $\chi^{*}=\chi_{s} \chi_{\infty} /\left(\chi_{s}-\chi_{\infty}\right) ; N_{i}$ is the concentration of ionized impurities; $N_{0}$ is the number of atoms in the volume unit; $\rho$ is the specific density of material; $v_{/ /}$is the rate of propagation of longitudinal acoustic waves; $E$ is the deformation potential constant; $W$ is a function that depends on the solid solution composition and the alloy potential of scattering that in the first approximation is equal to the difference in crystal sublattice energy gaps; $F_{\text {im }}, F_{\text {op }}, F_{\text {ac }}, F_{\text {dis }}$ are the functions that take into account the shielding of scattering center potential by free carriers and contain the Bloch multipliers taking into account the nonparabolicity of the material band structure. 


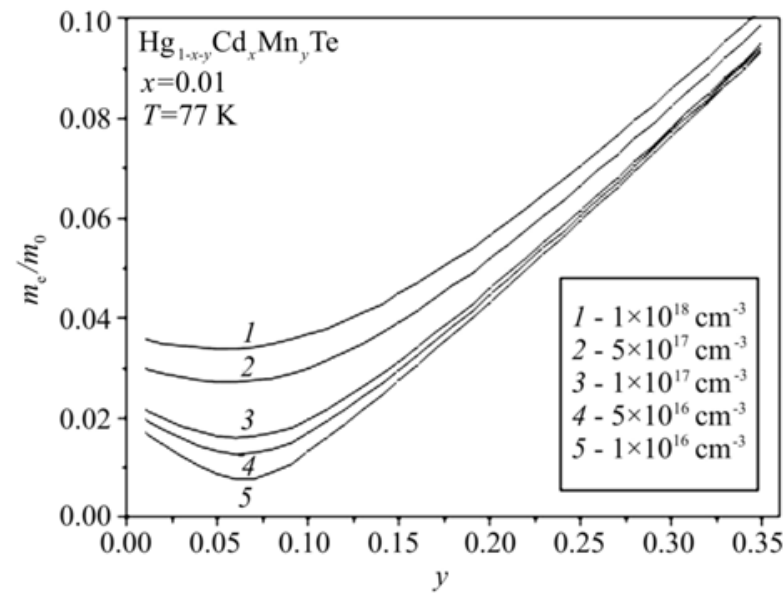

Fig. 4. Conduction electron mobilities at various scattering mechanisms as a function of temperature in the sample $\mathrm{Hg}_{0.9} \mathrm{Mn}_{0.1}$ Te with impurity concentrations: $N_{a}=5 \cdot 10^{15} \mathrm{~cm}^{-3}$, $N_{d}=1 \cdot 10^{15} \mathrm{~cm}^{-3}$. $(1-$ ionized impurities, $2-$ polar optical phonons, 3 - acoustic phonons, 4 - alloy potential, 5 - total mobility).

Fig. 4 shows the temperature dependence of the mobility calculated in accord with (8)-(11).

As can be seen from the figure, the greatest contribution to mobility formation in the temperature range of 80 to $300 \mathrm{~K}$ is made by scattering by polar optical phonons and ionized impurities. Scattering by the alloy potential and acoustic phonons is of little significance under these conditions, which is consistent with the papers [11, 12]. Therefore, our subsequent discussion will be restricted by two scattering mechanisms mentioned above. The results of mobility calculation under these conditions as compared to the experiment ones are shown in Fig. 5.

It can be seen that, with the selected calculation parameters, the results are in a good agreement with the experimental data, which confirms the correctness of assumptions made both with respect to band parameters and the dominating scattering mechanisms.

Fig. 6 shows calculated temperature dependences of conductivity and the Hall constant for several $\mathrm{Hg}_{1-\mathrm{x}-\mathrm{z}} \mathrm{Cd}_{\mathrm{x}} \mathrm{Zn}_{\mathrm{z}} \mathrm{Te}$ samples as compared with the experimental data.

One should note a rather high degree of coincidence between the theoretical and experimental data. Table 3

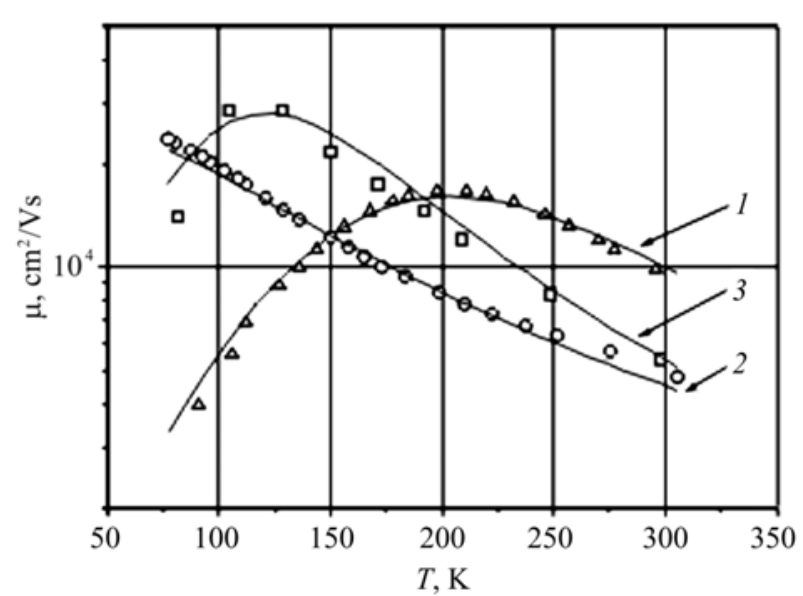

Fig. 5. Temperature dependence of the mobility: $1-\mathrm{Hg}_{1-x} \mathrm{Mn}_{x} \mathrm{Te}$ $\left(x=0,091 ; N_{a}=2 \cdot 10^{16} \mathrm{~cm}^{-3}\right) ; 2-\mathrm{Hg}_{1-x-y} \mathrm{Cd}_{x} \mathrm{Mn}_{y} \mathrm{Te}(x=0.1$; $\left.y=0.027 ; \quad N_{a}=3 \cdot 10^{15} \mathrm{~cm}^{-3}\right) ; 3-\mathrm{Hg}_{1-x-y-z} \mathrm{Cd}_{x} \mathrm{Mn}_{y} \mathrm{Zn}_{z} \mathrm{Te}$ $\left(x=0.14 ; \quad y=0.014 ; \quad z=0.01 ; \quad N_{a}=6 \cdot 10^{15} \mathrm{~cm}^{-3}\right)$. For all samples it is assumed that $N_{d}=10^{15} \mathrm{~cm}^{-3}$.

lists the values of parameters that were used in the calculation of theoretical dependences. The concentration of donor impurities was assumed to be equal to $10^{15} \mathrm{~cm}^{-3}$.

Table 3 gives shows the parameters of the samples of new five-component semiconductor solid solution $\mathrm{Hg}_{1-\mathrm{x}-\mathrm{z}} \mathrm{Cd}_{\mathrm{x}} \mathrm{Zn}_{\mathrm{z}} \mathrm{Te}$, studied by modeling the kinetic and band parameters. As can be seen, all the parameters of these samples: energy gap, acceptor concentration, impurity activation energy, are within the same range as that of better studied 3-4 component semiconductors of the same type: $\mathrm{HgCdTe}, \mathrm{HgMnTe}, \mathrm{HgCdMnTe}$.

The samples that were made of the first ingot of this material (the numbers begin with 1) in general have a lower concentration of manganese and zinc, and, hence, a narrower energy gap. The samples from the second ingot have a wider energy gap. As is evident from Fig. 6, exactly these samples (2.1.1 and 2.1.6) demonstrate a change in the Hall coefficient sign at sufficiently high temperatures $(200 \ldots 230 \mathrm{~K})$, which testifies to a wider energy gap and smaller concentration of intrinsic carriers. 1.3.3 sample is the most narrow-gap. It was cut from the crystal "tail" and have the highest acceptor concentration.

Table 3. Parameters of $\mathrm{Hg}_{1-\mathrm{x}-\mathrm{y}-\mathrm{z}} \mathrm{Cd}_{\mathrm{x}} \mathrm{Mn}_{\mathrm{y}} \mathrm{Zn}_{\mathrm{z}}$ Te crystals.

\begin{tabular}{|c|c|c|c|c|c|c|}
\hline \multirow{3}{*}{$\begin{array}{c}\text { Sample } \\
\mathrm{N}\end{array}$} & \multicolumn{2}{|c|}{$\begin{array}{c}\text { Composition of sample } \\
\mathrm{Hg}_{1-\mathrm{x}-\mathrm{y}-\mathrm{z}} \mathrm{Cd}_{\mathrm{x}} \mathrm{Mn}_{\mathrm{y}} \mathrm{Zn}_{\mathrm{z}} \mathrm{Te}\end{array}$} & \multirow{2}{*}{$N_{a}, \mathrm{~cm}^{-3}$} & \multirow{2}{*}{$E_{a}, \mathrm{meV}$} & $\begin{array}{c}\text { Energy gap } E_{g}, \\
\mathrm{eV}(T=300 \mathrm{~K})\end{array}$ \\
\cline { 2 - 4 } & $x$ & $y$ & $z$ & & & \\
\hline 1.2 .2 & 0.14 & 0.014 & 0.015 & $1 \cdot 10^{16}$ & 9 & 0.142 \\
1.3 .1 & 0.1 & 0.02 & 0.01 & $3.7 \cdot 10^{17}$ & 2 & 0.0949 \\
1.3 .3 & 0.01 & 0.005 & 0.005 & $1 \cdot 10^{18}$ & - & -0.098 \\
2.1 .1 & 0.23 & 0.05 & 0.02 & $7 \cdot 10^{15}$ & 15 & 0.3846 \\
2.1 .6 & 0.16 & 0.04 & 0.01 & $2.5 \cdot 10^{17}$ & 12 & 0.238 \\
1.1 .15 & 0.18 & 0.025 & 0.015 & $2 \cdot 10^{16}$ & 10 & 0.232 \\
\hline
\end{tabular}

(C) 2005, V. Lashkaryov Institute of Semiconductor Physics, National Academy of Sciences of Ukraine 

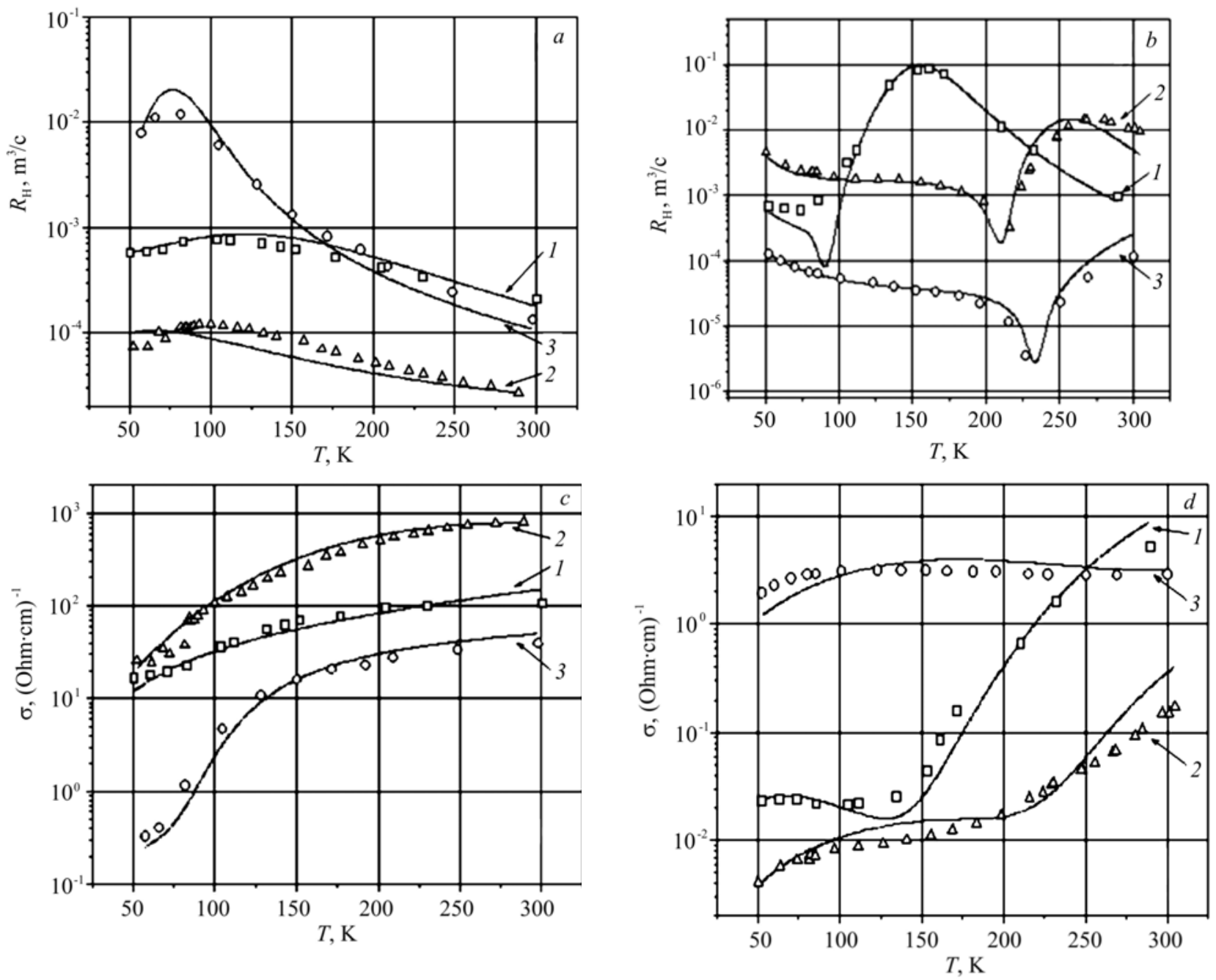

Fig. 6. Temperature dependences of the Hall constant $(a-b)$ and conductivity (c-d) for $\mathrm{Hg}_{1-\mathrm{x}-\mathrm{z}} \mathrm{Cd}_{\mathrm{x}} \mathrm{Zn}_{\mathrm{z}} \mathrm{Te}$ samples of different composition. a and c: 1 - sample 1.3.1, 2 - 1.3.3; 3 - 1.2.2. $\mathrm{b}$ and d: 1 - sample 1.1.15, 2-2.1.1;3-2.1.6.

The acceptor activation energy was obtained with the assumption that we deal with one acceptor level located not far from the valence band top and one donor level that we consider to be fully ionized at any temperature. As we see, the resulting values of the activation energy are within $2 \ldots 15 \mathrm{meV}$, which is typical for this class of semiconductors.

\section{Conclusions}

Thus, on the basis of the research performed, the following conclusions can be derived: the method for calculation of the basic band parameters of multicomponent solid solutions of HgCdTe type has been proposed.

1. The empirical formulae have been proposed for the calculation of the energy gap and intrinsic carrier concentration that are of the similar form for $\mathrm{HgCdMnTe}, \mathrm{HgCdZnTe}$, as well as $\mathrm{HgCdMnZnTe}$ - a new five-component solid solution and differ only in coefficients.

2. The effective mechanisms of charge carrier scattering in multicomponent semiconductors of $\mathrm{HgCdTe}$ type have been studied. It was shown that the main contribution to formation of the temperature dependence of the mobility is made by the carrier scattering caused by polar optical phonons and ionized impurities.

3. Temperature dependences of the Hall constant and conductivity in $\mathrm{HgCdMnZnTe}$ crystals of various composition have been calculated. The results of theoretical calculations are in a good agreement with the experimental data.

4. From the closest agreement between the theoretical and experimental curves, the activation energy and acceptor impurity concentration have been determined. 


\section{References}

1. A. Sher, A. Chen, W. Spicer, C. Shih, Effects influencing the structural integrity of semiconductors and their alloys // J. Vac. Sci. Technol. A3, p. 105-108(1985).

2. C.K. Williams, T.H. Glisson, J.R. Hauser, and M.A. Littlejohn, Energy bandgap and lattice constant contours of III-V quaternary alloys of the form $\mathrm{A}_{\mathrm{x}} \mathrm{B}_{\mathrm{y}} \mathrm{C}_{\mathrm{z}} \mathrm{D}$ or $\mathrm{AB}_{\mathrm{x}} \mathrm{C}_{\mathrm{y}} \mathrm{D}_{\mathrm{z}} / /$ J. Electron. Mater. $\mathrm{N} 7$, p. 639-646 (1978).

3. O.A. Bodnaruk, A.V. Markov, S.E. Ostapov, et al., Bandgap and intrinsic carrier concentration in HgCdMnTe and HgCdZnTe // Semiconductors 34, p. 415-417 (2000).

4. G.L. Hansen, J.L. Schmit, T.N. Cusselman, Energy gap versus alloy composition and temperature in $\mathrm{Hg}_{1-\mathrm{x}} \mathrm{Cd}_{\mathrm{x}} \mathrm{Te} / /$ J. Appl. Phys. 53, p. 7099-7102 (1982).

5. K. Joswikowski, A. Rogalski, Intrinsic carrier concentrations and effective masses in the potential infrared detector material HgZnTe // Infrared Phys. 28, p. 101-103 (1988).

6. O.A. Bodnaruk, I.N. Gorbatyuk, S.E. Ostapov, I.M. Rarenko, Intrinsic carrier concentration and effective mass of electrons in MnHgTe // Fiz. Tekhn. Poluprov. 26, Issue 3, p. 468-472 (1992) (in Russian).

7. S. Takeyama, S. Narita, The band structure parameters determination of the quaternary semimagnetic semiconductor alloy $\mathrm{HgCdMnTe} / / J$. Phys. Soc. Jpn 55, p. 274-278 (1986).

8. N.L. Bazhenov, A.M. Andrukhiv, V.I. IvanovOmskii, Carrier lifetime in $\mathrm{ZnCdHgTe}$ : Calculation and experiment // Infrared Phys. 34, N 4, p. 357-364 (1993).

9. J. Schmit, Intrinsic carrier concentration of $\mathrm{Hg}_{1-\mathrm{x}} \mathrm{Cd}_{\mathrm{x}} \mathrm{Te}$ as a function of $\mathrm{x}$ and $\mathrm{T} / / \mathrm{J}$. Appl. Phys. 41, N 7, p. 2876-2879 (1970).

10. A.I. Vlasenko, Ya.M. Olikh, and R.K. Savkina, Charge carrier mobility in $\mathrm{n}-\mathrm{CdHgTe}$ crystals subjected to dynamic ultrasonic stressing // Semiconductors 34 (6), p. 644-649 (2000).

11. I.M. Nesmelova, The optical properties of narrowgap semiconductors. Nauka, Novosibirsk (1992).

12. L.A. Kosyachenko, A.V. Markov, S.E. Ostapov, et al., The investigation of physical properties of p-type HgMnTe in the mixed conductivity region // Zhurn. Prikl. Spektrosk. 7, N 1, p. 101-105 (2003) (in Russian). 